\title{
A Hybrid of T-Dipole and Quasi-Yagi Antenna for Dual-band WLAN Access Point
}

\author{
Son Xuat Ta ${ }^{1}$, Ikmo Park ${ }^{1}$, Chien Dao-Ngoc ${ }^{2}$ \\ ${ }^{1}$ School of Electrical and Computer Engineering, Korea \\ ${ }^{2}$ Hanoi University of Science and Technology, Vietnam
}

Correspondence: Chien Dao-Ngoc, chiendn-fet@mail.hut.edu.vn

Manuscript communication: received 1 February 2012, accepted 4 July 2012

\begin{abstract}
In this paper, a hybrid of T-dipole and quasi-Yagi antenna is presented for using in dual-band Wireless Local Area Network (WLAN) access point. The antenna is made up of combination of T-dipole and quasi-Yagi antenna structures, which are distinctly designed to operate at 2.4 and $5.5 \mathrm{GHz}$ frequency bands. A simply integrated balun that consists of a curved microstrip line and a circular slot to allow broadband characteristic is used to feed the antenna. The final antenna design presents measured bandwidths $(R L \leq-10 \mathrm{~dB})$ of $2.35-2.55 \mathrm{GHz}$ and $4.30-6.56 \mathrm{GHz}$ which cover completely the two bands of WLAN. Simulated and measured results of peak gain and radiation patterns in both E- and H-plane validate potential of the design.
\end{abstract}

Keywords- Integrated balun, quasi-Yagi, T-dipole, wireless local area network (WLAN).

\section{INTRODUCTION}

In the last two decades, the $2.4 \mathrm{GHz}(2.4-2.484 \mathrm{GHz})$ and $5.5 \mathrm{GHz}(5.15-5.95 \mathrm{GHz})$ frequency bands have been widely used for the Wireless Local Area Network (WLAN) communication standards. Due to the presence of many shadowing areas as inside high buildings or tunnels, a large number of access points (APs) is needed to achieve ubiquitous coverage of WLAN systems. An AP is commonly attached on the wall or ceiling to provide coverage in a specified area. Therefore, the antenna for WLAN AP requires not only dualband operation but also an insignificant back-radiation. Several antennas [1]-[3] were reported for dual-band applications, including the printed dipole antennas [1], [2] or slot-monopole antenna [3]. However, these antennas have omni-directional radiation patterns, hence cannot prevent the radiated wave from propagating to undesired directions.

In recent years, both T-dipole and quasi-Yagi antennas have been widely employed in microwave and millimeter-wave applications owing to their broadband, simplicity, ease of fabrication, and low cost. While Tdipole antennas can be fed by various types of balun with [4]-[6] or without [4], [7], [8] via holes, quasiYagi antennas can be fed by alternative feeding lines, including microstrip line [9], coplanar waveguide [10], coplanar stripline [11], and slotline [12]. Especially, quasi-Yagi antennas have highly directional and endfire radiation pattern, which are promisingly suitable for WLAN APs. The main propose of this paper is to introduce a hybrid of T-dipole and quasi-Yagi antenna that is fed by a simply integrated balun consisting of a curved microstrip line and a circular slot. The Tdipole and quasi-Yagi antenna structures are distinctly designed to operate at $2.4 \mathrm{GHz}$ and $5.5 \mathrm{GHz}$ bands. The proposed antenna has a truncated ground and a parasitic director to improve its radiation pattern at the lower and upper bands, respectively.

\section{ANTENNA DESIGN AND CHARACTERISTICS}

Figure 1 shows the geometry of a hybrid of T-dipole and quasi-Yagi antenna. The antenna was designed on both sides of a $70 \times 50 \mathrm{~mm}$ Rogers $\mathrm{RO} 4003$ substrate with a dielectric constant of 3.38 and a thickness of $0.508 \mathrm{~mm}$. As can be seen, the antenna comprises of an integrated balun feeding, two printed dipoles, a parasitic strip, and a ground plane. The balun is composed of a curved microstrip line and a circular

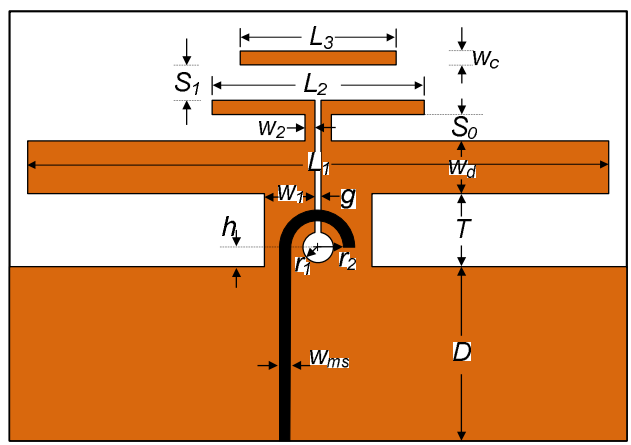

Figure 1. Geometry of the antenna. 
slot. The curved microstrip line was placed on the back side of the substrate, and comprised of a $50 \Omega$ feeding line and a half of ring both with $W_{m} s=1.14 \mathrm{~mm}$. The circular slot was etched on the printed dipoles with the same center of the ring. Initial lengths of the dipoles $L_{1}$ and $L_{2}$, and parasitic strip $L_{3}$ were approximately a half of the effective wavelength (i.e., $\left.\lambda_{e f f} / 2\right)$ at $2.45,4.8$ and $6.2 \mathrm{GHz}$, respectively. In this design, the ground plane will act as a reflector with a greater length than the larger dipole. The larger dipole was located at $T=8 \mathrm{~mm}$ away from the ground plane. The two dipoles were printed on the top side of the substrate with a spacing of $S_{0}=3 \mathrm{~mm}$. The spacing between the smaller dipole and the parasitic strip was $S_{1}=4 \mathrm{~mm}$. The antenna was optimized using the full-wave electromagnetic simulator Microwave Studio (MWS by Computer Simulation Technology - CST) to achieve dual-band characteristics and stable radiation pattern (i.e., moderate gain and high front-to-back ratio).

The T-dipole structure was separately designed for operating at $2.4 \mathrm{GHz}$ band, from which Figure 2 shows the reflection coefficient of the antenna as a function of the dipole length $\left(L_{1}\right)$. We can see that, as $L_{1}$ increases from 54 to $78 \mathrm{~mm}$ (in increment of $12 \mathrm{~mm}$ ) the resonance of $2.4 \mathrm{GHz}$ band decreases, and $L_{1}=66 \mathrm{~mm}$ provides the widest bandwidth at $5.5 \mathrm{GHz}$ band. These indicate that the length of the larger dipole mainly determines the resonant frequency of lower bands.

In the proposed antenna structure, the larger dipole, smaller dipole, and parasitic strip act as the reflector, driver, and director of the quasi-Yagi antenna, respectively. Figure 3 shows the reflection coefficient of the antenna as a function of the driver length $L_{2}$. As $L_{2}$ increases from 22 to $26 \mathrm{~mm}$ (in increments of $2 \mathrm{~mm}$ ), the $2.4 \mathrm{GHz}$ band hardly changes while the lower resonance of the $5.5 \mathrm{GHz}$ band decreases and the higher one remains almost the same. This indicates that the length of the driver mainly determines the lower resonance of the $5.5 \mathrm{GHz}$ band.

Figure 4 shows the reflection coefficient of the antenna as a function of the director length $L_{3}$. As $L_{3}$ increases from 16 to $19 \mathrm{~mm}$ (in increments of $1.5 \mathrm{~mm}$ ), the $2.4 \mathrm{GHz}$ band does not change while the higher resonance of the $5.5 \mathrm{GHz}$ band decreases and the lower one changed insufficiently. This indicates that the length of the director mainly determines the higher resonant frequency of the $5.5 \mathrm{GHz}$ band.

Figure 5 shows the reflection coefficient of the antenna as a function of the spacing between the driver and director $\left(S_{1}\right)$. Increments of $2 \mathrm{~mm}$ of this space from 2 to $6 \mathrm{~mm}$ induced significant changes in the reflection coefficient in the high-frequency region of the $5.5 \mathrm{GHz}$ band but negligible changes in the lowfrequency region and the $2.4 \mathrm{GHz}$ band. This indicates that the spacing between the driver and the director mainly affects the antenna characteristics in the highfrequency region of the $5.5 \mathrm{GHz}$ band.

As mentioned above, the T-dipole and quasi-Yagi antennas were distinctly designed for $2.4 \mathrm{GHz}$ and $5.5 \mathrm{GHz}$, however, an existing influence between two.

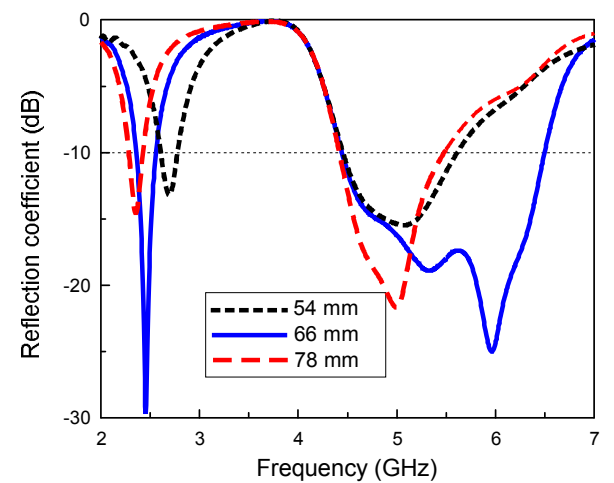

Figure 2. Reflection coefficient as a function of $L_{1}$.

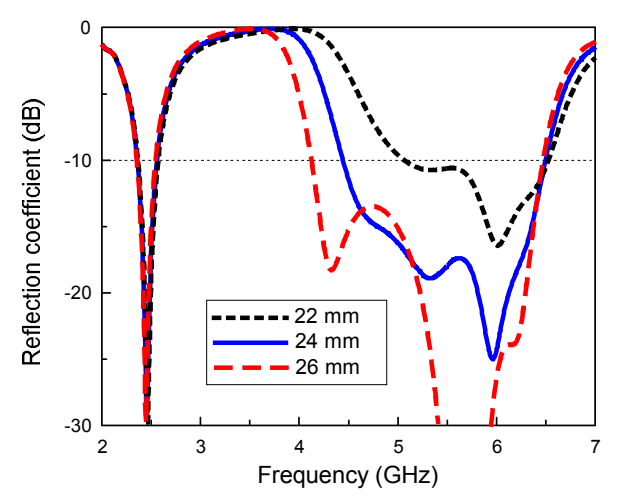

Figure 3. Reflection coefficient as a function of $L_{2}$.

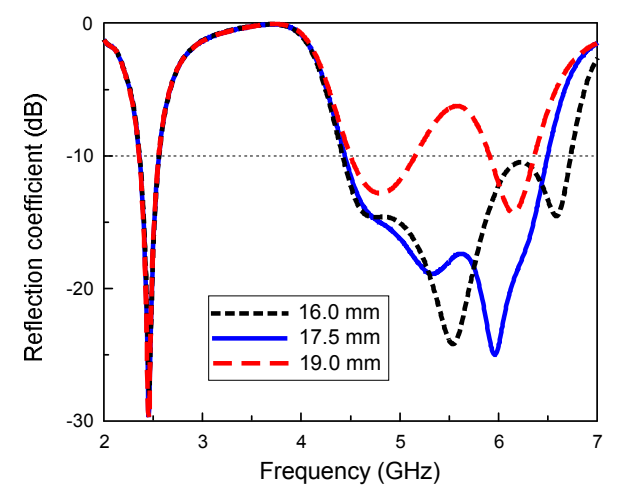

Figure 4. Reflection coefficient as a function of $L_{3}$.

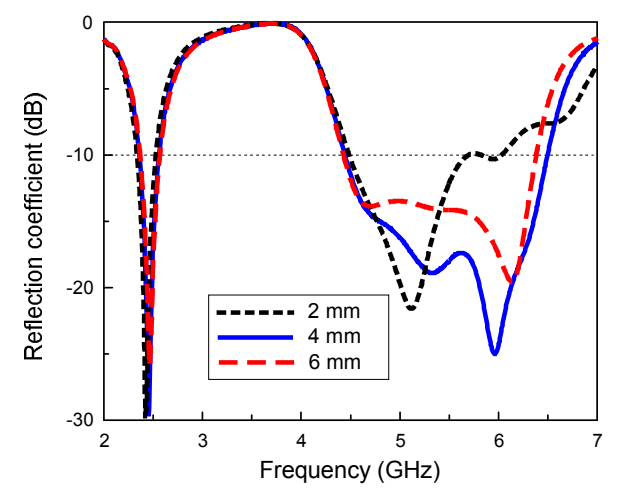

Figure 5. Reflection coefficient as a function of $S_{1}$. 


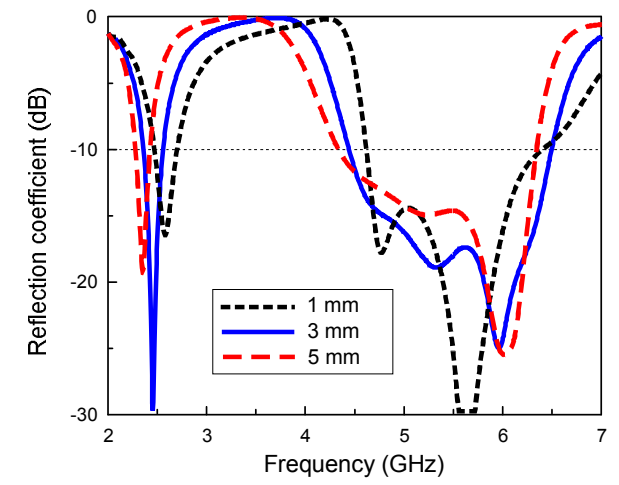

Figure 6. Reflection coefficient as a function of $S_{0}$.

This can be seen from Figure 6, which shows the reflection coefficient of the antenna as a function of the spacing between the large and small dipoles $\left(S_{0}\right)$. As $S_{0}$ was increased from 1 to $5 \mathrm{~mm}$ (in increments of $2 \mathrm{~mm}$ ), the resonance of the $2.4 \mathrm{GHz}$ band decreased while the center frequency of the $5.5 \mathrm{GHz}$ band insignificantly changed. This indicates that a judicious choice of the spacing $\left(S_{1}\right)$ is very important for dual-band operation of the proposed antenna.

The antenna was fabricated using a standard etching technology on Rogers RO4003 substrate with a $20 \mu \mathrm{m}$ copper thickness, and a subminiature type-A (SMA) connector was used as a microstrip-to-coaxial line transition (not included in the simulations). An Agilent N5230A network analyzer was first calibrated with an Agilent $3.5 \mathrm{~mm}$ 85052B calibration kit and then used to measure the prototype shown in Figure 7. As shown in Figure 8, the measured reflection coefficient of the optimized antenna is in a very good agreement with the simulation. The measured bandwidth was $2.35-$ $2.55 \mathrm{GHz}$ and $4.30-6.56 \mathrm{GHz}$ for the $-10 \mathrm{~dB}$ reflection coefficient while the simulated bandwidth was 2.36 $2.56 \mathrm{GHz}$ and $4.45-6.49 \mathrm{GHz}$. This bandwidth completely covers the specification for WLAN operation in the $2.4 \mathrm{GHz}(2.4-2.484 \mathrm{GHz})$ and $5.5 \mathrm{GHz}(5.15-$ $5.95 \mathrm{GHz}$ ) bands.

The radiation patterns and gain of the proposed antenna were measured with an Agilent E8362B network analyzer. Two identical standard horn antennas (one for transmitting and one for receiving) were first connected to two ports of the network analyzer for calibration. The distance between the transmitting and receiving antennas was $10 \mathrm{~m}$. The receiving antenna was then replaced with the hybrid of T-dipole and quasi-Yagi antenna. In the measurement process, the transmitting antenna was fixed, while the receiving antenna was rotated from $-180^{\circ}$ to $180^{\circ}$, with an angular increment of $1^{\circ}$. Figure 9 shows 2.45, 5, 5.5, and $6 \mathrm{GHz}$ radiation patterns of the antenna and showed a good agreement between the measurements and simulations. The patterns are quite symmetric and stable for both of lower and upper bands. At the frequency of $2.45 \mathrm{GHz}$, the measurements resulted in a front-to-back ratio of $14 \mathrm{~dB}$ and a half-power beamwidth (HPBW) of $66^{\circ}$ and
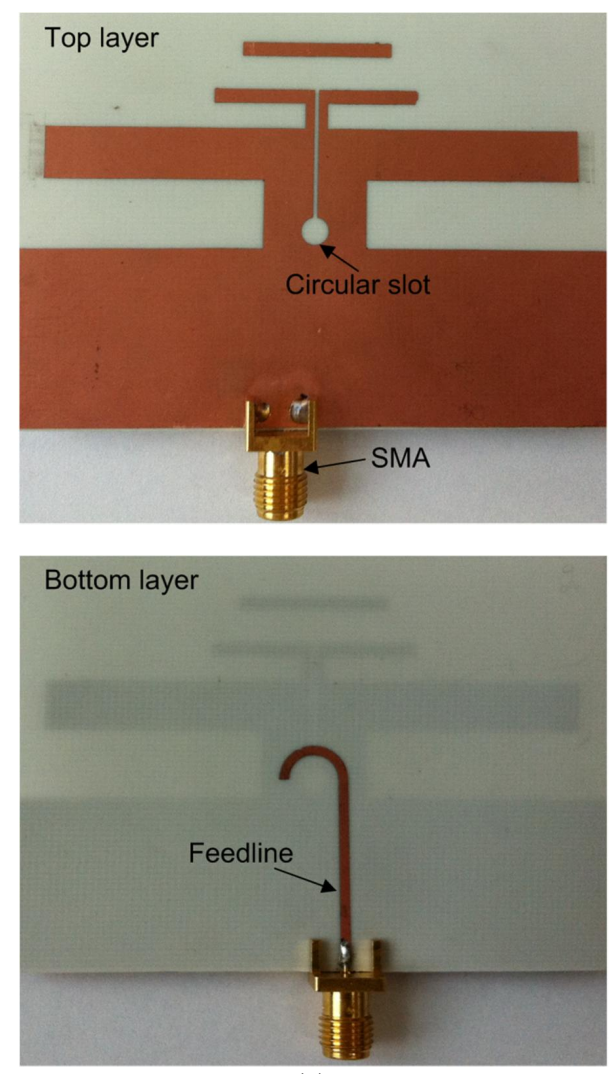

Figure 7. Fabricated antenna.

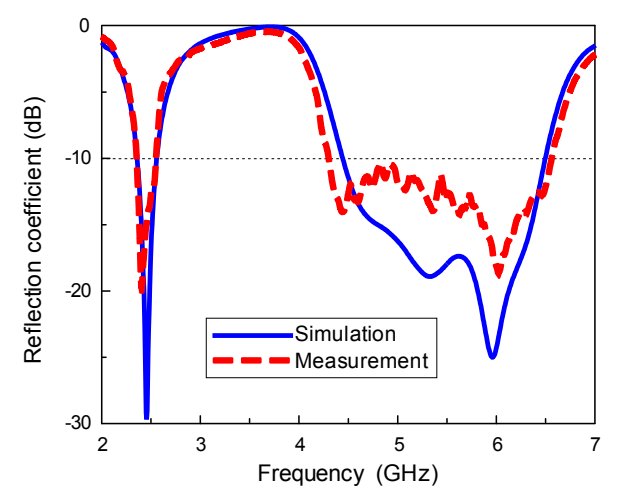

Figure 8. Measured and simulated reflection coefficient.

$162^{\circ}$ along E- and H-plane patterns, respectively. At $5.5 \mathrm{GHz}$ band, the measurements resulted in a frontto-back ratio of $>25 \mathrm{~dB}$, HPBWs of $42^{\circ}-67^{\circ}$ and $148^{\circ}-182^{\circ}$ along the E- and H-plane, respectively. As shown in Figure 10, a slight difference between the measured and simulated gain could be attributed to a misalignment between curved microstripline and the circular slot of the balun and effect of the SMA connector. Additionally, the measurement resulted in the peak gains of 5.83 and $7.44 \mathrm{dBi}$ for the $2.4 \mathrm{GHz}$ and $5.5 \mathrm{GHz}$ bands, respectively. 


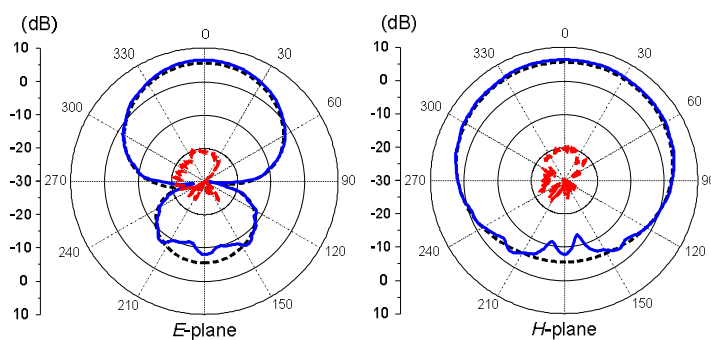

(a)

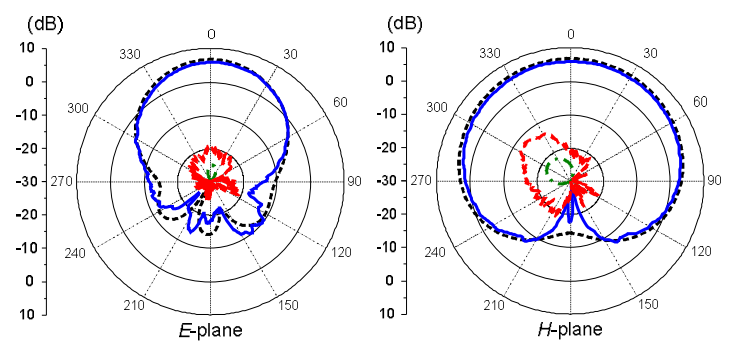

(b)

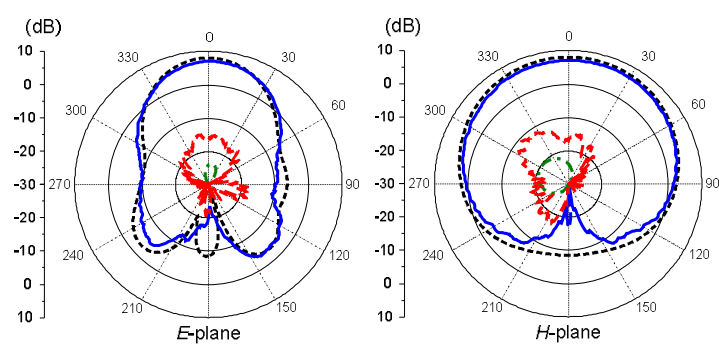

(c)

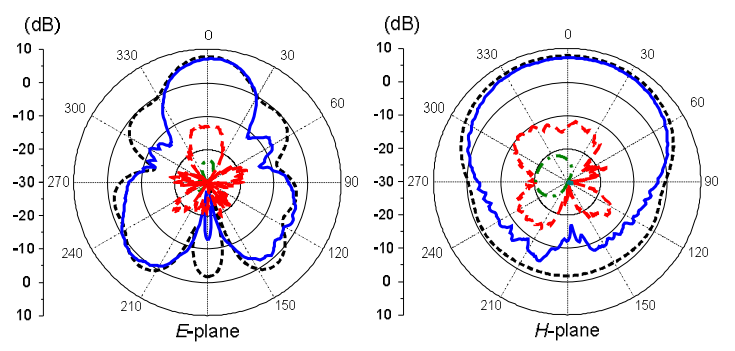

(d)

Figure 9. (a) 2.45, (b) 5.0, (c) 5.5, and (d) $6.0 \mathrm{GHz}$ radiation patterns of the antenna.

\section{Conclusions}

Hybrid of T-dipole and quasi-Yagi antenna with single feed introduced for use in the dual-band WLAN access points. T-dipole and quasi-Yagi antenna are designed to operate at $2.4 / 5.5 \mathrm{GHz}$ bands, respectively. The single feed is a simple integrated balun with a curved microstripline and a circular slot. The antenna has an impedance matching bandwidth of $2.355-2.565 \mathrm{GHz}$ and $4.4-6.6 \mathrm{GHz}$ for the $-10 \mathrm{~dB}$ reflection coefficient. The peak gains are 5.83 and $7.44 \mathrm{dBi}$ for the lower

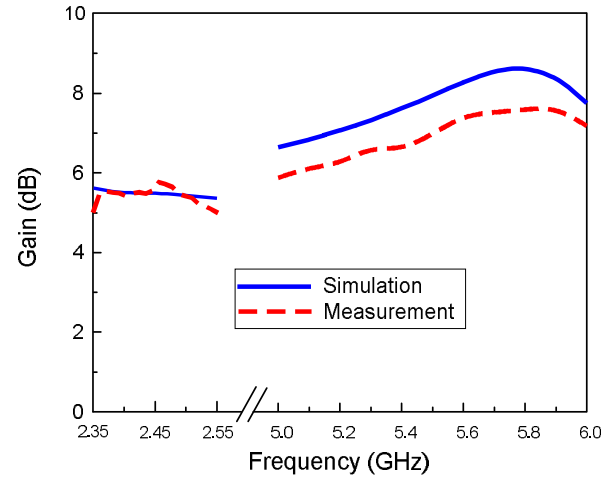

Figure 10. The gain of the proposed antenna.

and upper bands, respectively. This simple structure, dual-band, and quite stable radiation pattern make the proposed antenna can be widely used in WLAN access points.

\section{REFERENCES}

[1] E. Avila-Navarro, C. Cayuelas, and C. Reig, "Dual-band printed dipole antenna for Wi-Fi 802.11n applications," Electronics Letters, vol. 46, no. 21, pp. 1421-1422, 2010.

[2] N. Zhang, P. Li, B. Liu, X. W. Shi, and Y. J. Wang, "Dual-band and low cross-polarisation printed dipole antenna with L-slot and tapered structure for WLAN applications," Electronics Letters, vol. 47 , no. 6, pp. 360-361, 2011.

[3] C.-Y. Huang and E.-Z. Yu, "A slot-monopole antenna for dualband WLAN applications," IEEE Antennas and Wireless Propagation Letters, vol. 10, pp. 500-502, 2011.

[4] R. L. Li, T. Wu, B. Pan, K. Lim, J. Laskar, and M. M. Tentzeris, "Equivalent-circuit analysis of a broadband printed dipole with adjusted integrated balun and an array for base station applications," IEEE Transactions on Antennas and Propagation, vol. 57, no. 7, pp. 2180-2184, 2009 .

[5] E. Avila-Navarro, J. Anton, J. M. Blanes, and C. Reig, "Broadband printed dipole with integrated via-hole balun for WiMAX applications," Microwave and Optical Technology Letters, vol. 53, no. 1, pp. 52-55, 2011.

[6] W. S. Yeoh, K. L. Wong, and W. S. T. Rowe, "Wideband miniaturized half bowtie printed dipole antenna with integrated balun for wireless applications," IEEE Transactions on Antennas and Propagation, vol. 59, no. 1, pp. 339-342, 2011.

[7] P. Lindberg, E. Ojefors, Z. Barna, A. Thornell-Pers, and A. Rydberg, "Dual wideband printed dipole antenna with integrated balun," IET Microwaves, Antennas \& Propagation, vol. 1, no. 3, pp. 707-711, 2007.

[8] Q.-Q. He, B.-Z. Wang, and J. He, "Wideband and dual-band design of a printed dipole antenna," IEEE Antennas and Wireless Propagation Letters, vol. 7, pp. 1-4, 2008.

[9] Y. Qian, W. R. Deal, N. Kaneda, and T. Itoh, "Microstrip-fed quasi-Yagi antenna with broadband characteristics," Electronics Letters, vol. 34, no. 23, pp. 2194-2196, 1998.

[10] L. H. Truong, Y.-H. Baek, M.-K. Lee, S.-W. Park, S.-J. Lee, and J.-K. Rhee, "A high-performance $94 \mathrm{GHz}$ planar Quasi-Yagi antenna on GaAs substrate," Microwave and Optical Technology Letters, vol. 51, no. 10, pp. 2396-2400, 2009.

[11] K. Han, Y. Park, H. Choo, and I. Park, "Broadband CPS-fed YagiUda antenna," Electronics Letters, vol. 45, no. 24, pp. 1207-1209, 2009.

[12] S. X. Ta, B. Kim, H. Choo, and I. Park, "Slot-line-fed quasiyagi antenna," in The 9th International Symposium on Antennas, Propagation, and EM Theory, Guangzhou, China 2010. 


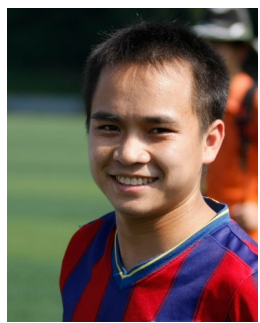

Son Xuat Ta received the Diploma of Engineer in Electronics and Telecommunications from Hanoi University of Science and Technology, Hanoi, Vietnam in 2008. He is currently pursuing Ph.D degree at the School of Electrical and Computer Engineering, Ajou University, Suwon, Korea. His research interests have been focused on the widebands, multiband, and UWB antennas for the next generation wireless communication systems.

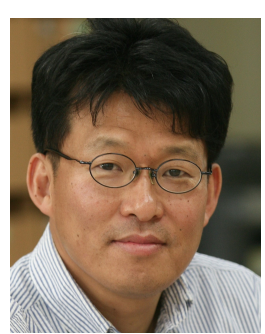

Ikmo Park received the B.S degree in Electrical Engineering from the State University of New York at Stony Brook in 1984, and the M.Sc and Ph.D degrees in Electrical Engineering from the University of Illinois at Urbana-Champaign in 1989 and 1994, respectively. From 1994 to 1996, he worked for LG Corporate Institute of Technology. Since 1996, he has been a professor of the School of Electrical and Computer Engineering at Ajou University, Suwon, Korea. His research interests include design and analysis of terahetz and microwave passive devices and antennas.

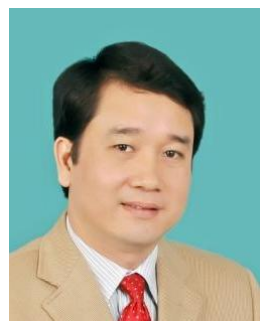

Chien Dao-Ngoc received the Diploma of Engineer in 1997 from the Department of Telecommunication Systems, School of Electronics and Telecommunications, Hanoi University of Science and Technology, where in the same year he became a Teaching Assistant. He received M.Sc. and Ph.D. degrees in 2002 and 2005, respectively, from the Department of Electronics and Computer Engineering, Gifu University, Japan. At the Department of Telecommunication Systems, School of Electronics and Telecommunications, Hanoi University of Science and Technology, he worked as the Senior Lecturer from 2005 to 2011, and is currently the Contracted Lecturer. He has been appointed to Associate Professor since November, 2010.

His research interests include computational electromagnetics based on MoM and FDTD methods, analysis and design of modern antennas and of nanometric integrated optical circuits based on the surface plasmon polaritons. He has been a reviewer for several journals/transactions of Optical Society of America (OSA), Institute of Electrical and Electronics Engineers (IEEE), Elsevier, and American Geophysical Union (AGU), as well as for a number of conferences. He has been a member of IEEE, OSA and REV. 